\title{
Growth features of Juniperus excelsa M. Bieb. in the conditions of field vegetation experiment and in greenhouse on the Southern Coast of the Crimea
}

\author{
$O$ Ilnitsky $^{1}, Y$ Plugatar $^{2}, A$ Pashtetsky $^{1, *}$, and $S$ Korsakova $^{1}$ \\ ${ }^{1}$ The Nikitsky Botanical Gardens - National Scientific Center of the RAS, Laboratory of \\ Phytomonitoring, 52 Nikitsky spusk st., Nikita, Yalta, 298648, Russian Federation \\ ${ }^{2}$ The Nikitsky Botanical Gardens - National Scientific Center of the RAS, Department of Natural \\ Ecosystems, 52 Nikitsky spusk st., Nikita, Yalta, 298648, Russian Federation
}

\begin{abstract}
Different climatic conditions of the greenhouse and open ground determine the growth characteristics of Juniperus excelsa M. Bieb. During the studied vegetation period, three periods of trunk diameter growth were observed in the field vegetation experiment: in March-May, two growth peaks - at the first peak $-1 \%(0.68 \mathrm{~mm})$, at the second one $8.83 \%(3.72 \mathrm{~mm})$. In July-August by $4.74 \%(1.69 \mathrm{~mm})$, and in SeptemberOctober by $4.9 \%-(1.53 \mathrm{~mm})$, the increase in the trunk diameter for 2019 was $18.96 \%$ or $7.62 \mathrm{~mm}$. In greenhouse conditions, there were two growth peaks: in March-July, the first peak was an increase in d,\% by $7.12 \%(1.11$ $\mathrm{mm}$ ) - while there was a slowdown in growth (April, 28 -May, 27) and (July, 13 - July, 25). The second peak is an increase in d, $\%$ by $5.06 \%$ - and a slowdown in growth (November, 05 - November, 14). Total increase in $\mathrm{d}, \%$ was $12.18 \%(1.899 \mathrm{~mm})$. The increase in $\mathrm{d}, \%$ in the conditions of vegetation experiment is $6.48 \%$ more than in the greenhouse conditions. Optimal and limiting values of the studied parameters of the environment and $\mathrm{d}, \%$ for both research variants are found, and equations of nonlinear dependence between them are constructed. An increase in air temperature to $30-35^{\circ} \mathrm{C}$ causes a decrease in growth intensity. The research made it possible to determine the optimal and limiting conditions for the growth of this species in the conditions of the Southern Coast of the Crimea and the possibility of its introduction to other regions.
\end{abstract}

\section{Introduction}

In the conditions of increasing aridization of the territory of the Southern Coast of the Crimea (SCC) and in connection with global climate change [1-2], the study of ecological and physiological features of rare and protected species is a necessary basis for their conservation, development of an environmentally sound system of protection and maintenance of bioecological potential. One of these species is the high juniper (Juniperus

\footnotetext{
*Corresponding author: a.v.pashtetskii@gmail.com
} 
excelsa M. Bieb.). There are known works about the conditions of growth of this species in the conditions of the SCC [3]. The papers show the features of the structure of phytocenoses of Junipereta excelsae formation in the Mountainous Crimea. The main regularities of the formation of plantings of this species in the reserve "Cape Martyan" and the forecast of their further development are described in the work [3]. the analysis of the age structure of the juniper population with alternating wet and dry multi-year periods is given.

In the Mediterranean, where this species grows, studies have been conducted to determine environmental characteristics and their seasonal variability [4], as well as to model the dynamics of forests in the Taurus -Turkey mountains [5]. There are known studies on the habitat of Juniperus excelsa in southwestern Anatolia along the gradient between the Mediterranean and continental climate [6-8].

Features of the water regime in introduced species allow us to determine the degree of adaptation of plants to certain environmental conditions [9].

The aim of the work was to study the dependencies of the growth intensity of Juniperus excelsa M. Bieb. from the main environmental factors during the growing season of plants under greenhouse and field experiment that allows to determine the optimum and limiting conditions for growing this species in terms of the SCC.

\section{Materials and method}

High juniper - Juniperus excelsa M. Bieb. - in the Crimea grows from Cape Aya to Karadag, as well as in the Baydar valley. J. excelsa is an evergreen coniferous tree or shrub 10-15 m high and it grows in the lower mountain belts to a height of $400 \mathrm{~m}$ above sea level on sunny dry slopes, especially on calcite soils. The reproductive cycle (from the initiation of cones to the maturation of seeds) in the Crimea is 27 months. Dusting occurs from midJanuary to April [3].

The research was conducted in greenhouses on the territory of the Central Department of the Nikitsky Botanical Gardens. Plants-seedlings 3-4 years old were grown from cuttings. The time of the experiments is 2017-2019. In the course of research to find the relationships between the main weather factors and the growth of the trunk, plants were irrigated to the soil humidity of $80-90 \%$ of minimum moisture-holding capacity.

To measure the characteristics of the environment, a wireless phytomonitoring system was used, which includes PM-11z phytomonitor of "Bioinstruments S.R.L.", a USB adapter and a set of wireless sensors: DWS-11z weather station - a measuring complex that combines a pyranometer (Apogee Instruments, USA), a temperature and humidity sensor, a rain gauge (Decagon Devices, USA) and an anemometer (Davis Instruments (USA). Changes in the diameter of the trunk (shoot) were carried out by dendrometers [10] - FI-Sz, SD-10z sensors, connected to the wireless system of the PM-11z Phytomonitor. [11] Statistical data processing was performed using the application computer programs Statistica 10 ("Statsoft Inc.", USA) and Microsoft Excel 2010. Least squares and robust locally weighted regression (Statistica 10) methods are used for modeling and smoothing two-dimensional data. All calculations were performed at a given significance level $\mathrm{P} \leq 0.05$.

\section{Results and discussion}

A series of experiments conducted during the vegetation of a plant in greenhouse and field vegetation experiment conditions allowed us to determine the optimal and limiting factors for the growth of this species in the conditions of the SCC. 
Different climatic conditions of greenhouses and open ground determine the growth characteristics of Juniperus excelsa M. Bieb. (fig.1).

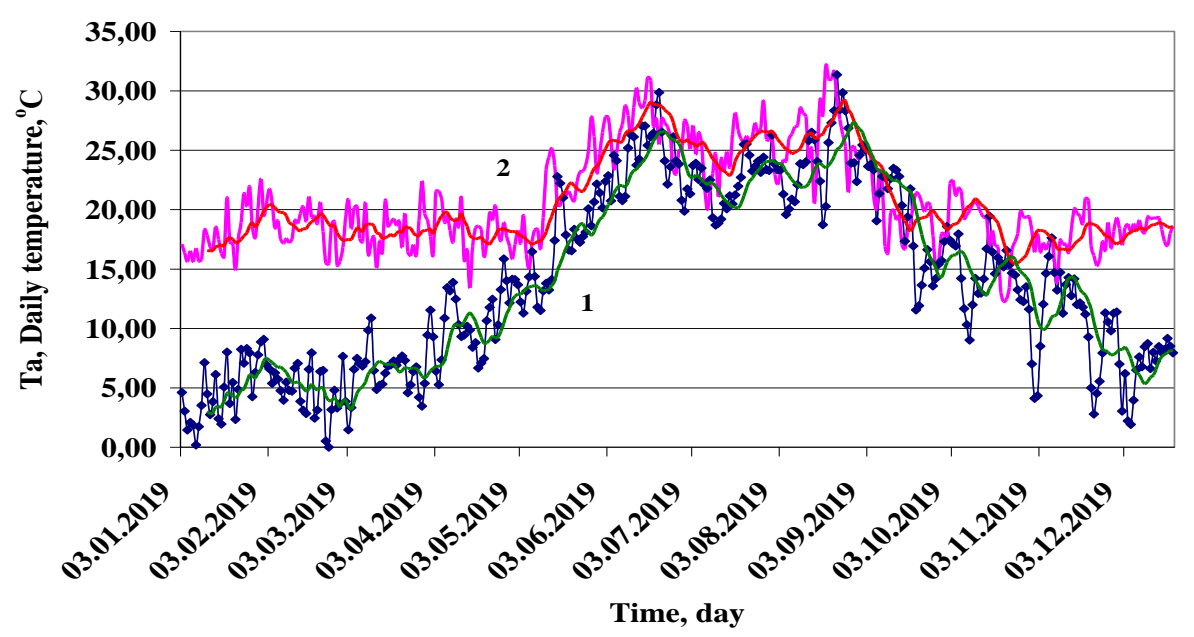

Fig. 1. Sums of daily temperatures (1) and their average daily values (2) and trend line for 2019.

The growth of the plant trunk is an integral indicator that characterizes the physiological state of the plant and the relationship of its life processes with the main environmental factors [12-15].

A series of studies were conducted during 2017-2019 to determine the growth characteristics of the trunk diameter in different periods of vegetation of the species-before the beginning of vegetation, the active growth phase and the end of vegetation. The results of research in the field vegetation experiment and greenhouse for 2019 are shown below.

In our studies, changes in the trunk diameter were measured relative to its value at the beginning of the experiment (the base value) in relative units (\%) and absolute ( $\mathrm{mm})$. The diameter of the trunk of Juniperus excelsa M. Bieb. in the field vegetation experiment at the beginning of the experiment was equal to $35.67 \mathrm{~mm}$. The study of these relationships was carried out in different periods of vegetation of the species - in spring (March-May), summer (July - August) and autumn (September-October). These periods are characterized by different intensity of meteorological factors - air temperature, solar radiation, and lack of air humidity $[9,16]$. The highest intensity of these parameters was observed in May-June and July-August (fig. 1).

The dynamics of growth intensity of the trunk of Juniperus excelsa M. Bieb is shown and the relationship of this process with environmental factors in March - May 2019 (fig. 2). 
A
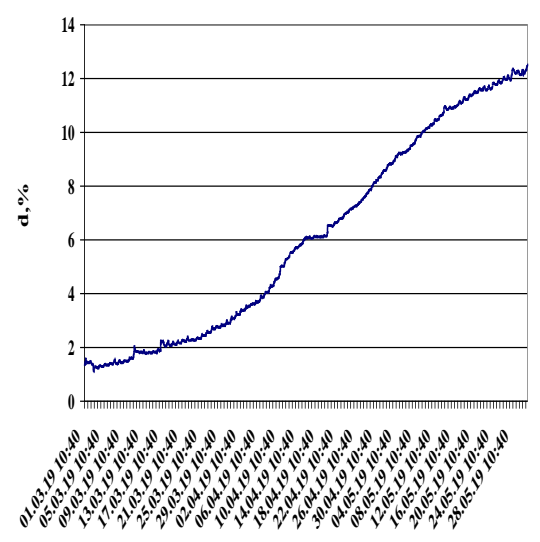

Time, day

$\mathrm{C}$

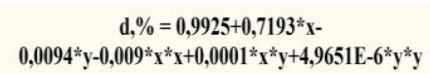

B

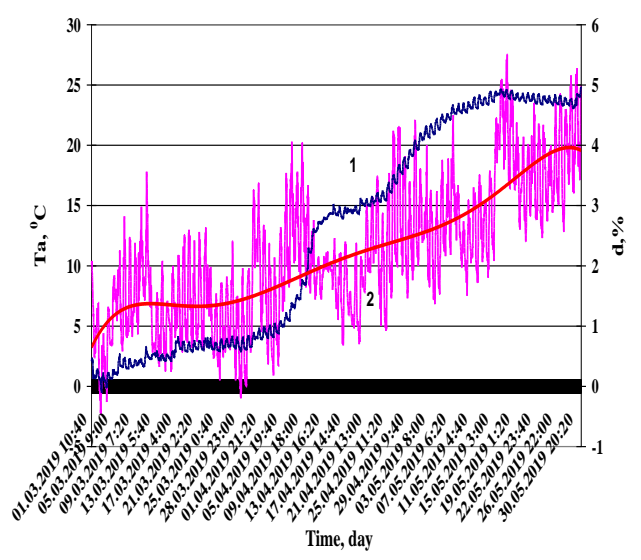

$\mathrm{D}$

$\mathrm{d}, \%=6,1095-0,3233 * \mathrm{x}-0,0013 * \mathrm{y}+$ $2,425^{*} x^{*} x-0,0032 * x^{*} y+4,0157 \mathrm{E}-6^{*} y^{*} y$

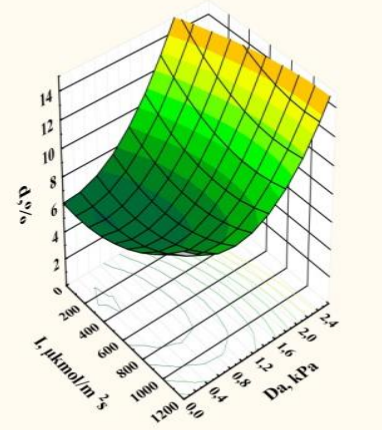

Fig. 2. Dynamics of trunk growth rate Juniperus excelsa M. Bieb. and the relationship of this process with environmental factors in March-May 2019. : A - features of the growth of the diameter of the trunk (d,\%); B - natural changes in the parameters d,\% (2) and air temperature (1) and trend line; C is the surface of a quadratic function $\mathrm{d}, \%=\mathrm{f}(\mathrm{I}, \mathrm{Ta})$; and $\mathrm{d}, \%=\mathrm{f}(\mathrm{I}, \mathrm{Da})-\mathrm{D}$; the top of the graph shows the numerical coefficients of the nonlinear regression equations of these dependencies.

Features of the trunk growth intensity of the studied species for March - May are shown (fig. 2, A). There are three peaks of change in this parameter: the first peak - March, 1April, 2 - the beginning of growth, the second peak - April, 2 - May, 28 - intensive growth, the third one - after May, 28 - reaching the growth plateau. At the first peak, the increase was $1 \%(0.68 \mathrm{~mm})$, at the second $-8.83 \%(3.72 \mathrm{~mm})$ with further access to the plateau.

The dynamics of trunk growth synchronously with changes in air temperature are shown (fig. 2, B). At the first peak of growth, the average daily temperature varied from 3.5 to $7.5^{\circ} \mathrm{C}$, which led to a $1 \%$ change in diameter. A further increase in temperature to 27 $28^{\circ} \mathrm{C}$ caused a sharp increase in the intensity of growth, followed by an exit to the plateau.

The dependence of the growth intensity on the total solar radiation and air temperature is $\mathrm{d}, \%=\mathrm{f}(\mathrm{I}, \mathrm{Ta})$ and the nonlinear regression equation for these dependencies is shown (fig. $2, \mathrm{C})$. The intensity of growth is a function of the response to the impact of the studied environmental factors. This "optimum zone" includes points with a growth intensity value 
greater than $90 \%$ of dmax. This allowed us to determine the optimal and limiting conditions of maxima and the boundaries of the regions of growth optima and the numerical coefficients of nonlinear regression equations of these dependencies [16-17]. Optimal air temperature $\mathrm{Ta}=20-26^{\circ} \mathrm{C}, \mathrm{I}=300-900 \mu \mathrm{mol} / \mathrm{m} 2 \mathrm{~s}$.

The dependence of growth intensity on total solar radiation and air humidity deficit $\mathrm{d}, \%=\mathrm{f}(\mathrm{I}, \mathrm{Da})$ and the nonlinear regression equation are shown (fig. 2, D). For this vegetation period, the optimal parameters are $\mathrm{Da}=0.4-1.2 \mathrm{kPa}, \mathrm{I}=400-1000 \mu \mathrm{mol} / \mathrm{m} 2 \mathrm{~s}$.

The change in parameter $\mathrm{d}, \%$ depends on the air temperature. An increase in air temperature to $30-35^{\circ} \mathrm{C}$ caused a decrease in the intensity of growth, followed by the reaching the plateau (fig. 3, B).

The dependence of growth intensity on total solar radiation and air temperature $\mathrm{d} \%=\mathrm{f}(\mathrm{I}, \mathrm{Ta})$ is shown, and the equation of nonlinear regression of these dependencies is given (fig. 3, C). The optimal conditions for maxima and the boundaries of the optimal regions are $\mathrm{Ta}=22-28^{\circ} \mathrm{C}, \mathrm{I}=500-1000 \mu \mathrm{mol} / \mathrm{m} 2 \mathrm{~s}$.

The dependence of growth intensity on total solar radiation and air humidity deficit $\mathrm{d}, \%=\mathrm{f}(\mathrm{I}, \mathrm{Da})$ is shown, and the equation of nonlinear regression of these dependencies is given (fig. 3, D). Optimal and limiting conditions of maxima and boundaries of growth optima regions and numerical coefficients of nonlinear regression equations of these dependencies are determined $-\mathrm{Da}=1.8-2.5 \mathrm{kPa}, \mathrm{I}=500-1000 \mu \mathrm{mol} / \mathrm{m} 2 \mathrm{~s}$. 
A

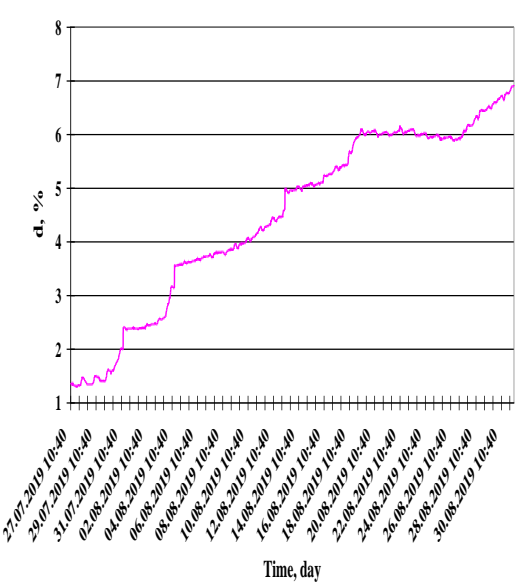

C

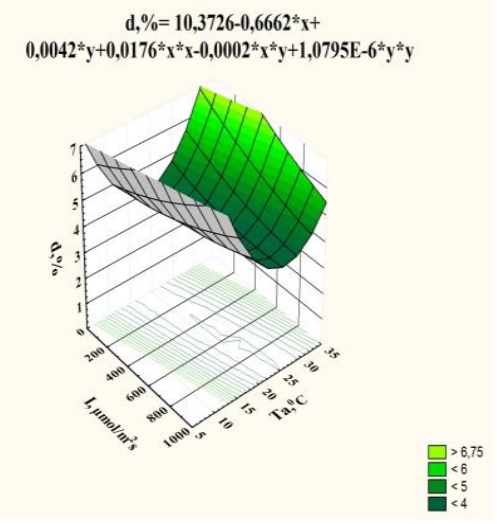

B

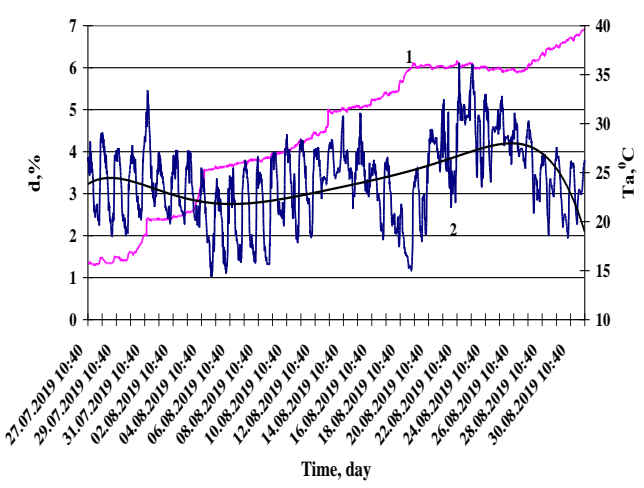

$\mathrm{D}$

d, $\%=5,4479-0,0645 * x-2,4882 E-5 * y+0,0097 * x * x+0,0003 * x * y$ $-3,7279 \mathrm{E}-7^{*} \mathrm{y}^{*} \mathrm{y}$

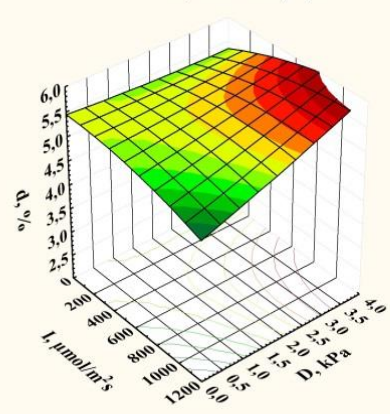

Fig. 3. Dynamics of trunk growth rate of Juniperus excelsa M. Bieb. and the relationship of this process with environmental factors in July-August 2019: A - features of the growth of the diameter of the trunk (d,\%); B - natural changes in the parameters d,\% (2) and air temperature (1) and trend line; $\mathrm{C}-$ is the surface of a quadratic function $\mathrm{d}, \%=\mathrm{f}(\mathrm{I}, \mathrm{Ta})$ and $\mathrm{d}, \%=\mathrm{f}(\mathrm{I}, \mathrm{Da}))-\mathrm{D}$; the top of the graph shows the numerical coefficients of the nonlinear regression equations of these dependencies.

The change in the growth rate of the trunk of the studied species and the parameters of the external environment for the months of September - October is shown (fig. 4). There are also two peaks of change in this parameter: the first peak on September, 1 -October, 14 - intensive growth of d,\% by $4.39 \%(1.53 \mathrm{~mm})$, the second one - after October, $14-$ reaching the growth plateau (fig. $4, \mathrm{~A}$ ). In this case, there is a dependence of the change in parameter $\mathrm{d}, \%$ of the air temperature. A decrease in the air temperature in October to 10$12^{\circ} \mathrm{C}$ caused a decrease in the intensity of growth, followed by an exit to the plateau (fig. 4 , B).

The dependence of the growth intensity on the total solar radiation and air temperature is determined $-\mathrm{d}, \%=\mathrm{f}(\mathrm{I}, \mathrm{Ta})$ and the equation of nonlinear regression of these dependencies is given (fig. 4, C). This allowed us to determine the optimal and limiting conditions of maxima and the boundaries of the optimal growth areas $-\mathrm{Ta}=17-25^{\circ} \mathrm{C}, \mathrm{I}=400-800$ $\mu \mathrm{mol} / \mathrm{m} 2 \mathrm{~s}$.

The dependence of the growth intensity on the total solar radiation and air humidity deficit $-\mathrm{d}, \%=\mathrm{f}(\mathrm{I}, \mathrm{Da})$ is studied and the equation of nonlinear regression of these 
dependencies is given (fig. 4, D). This allowed us to determine the optimal and limiting conditions of the maxima: $\mathrm{Da}=0.3-1.5 \mathrm{kPa}, \mathrm{I}=400-800 \mu \mathrm{mol} / \mathrm{m} 2 \mathrm{~s}$.

A

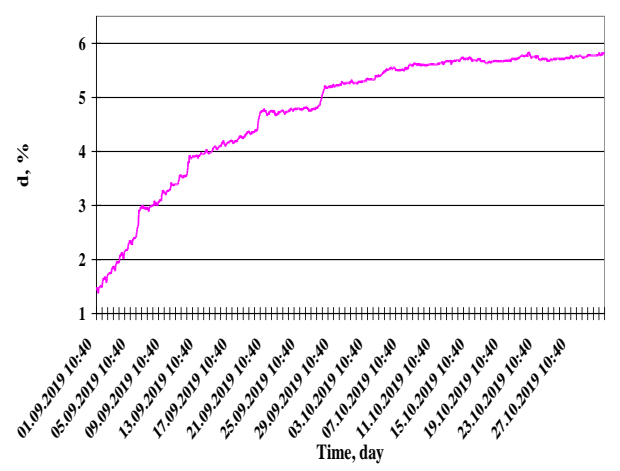

$\mathrm{C}$

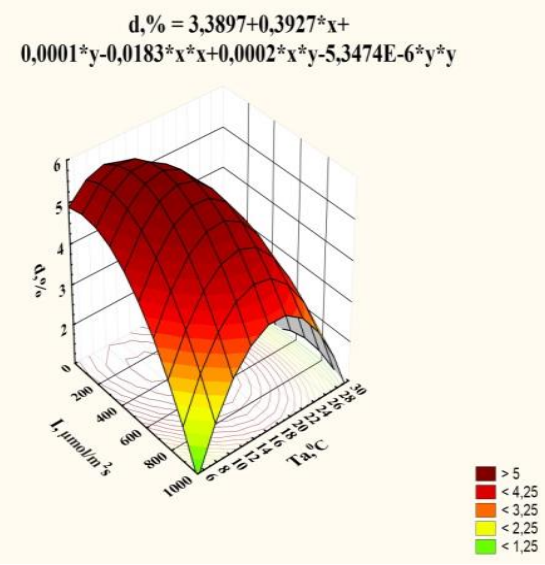

B

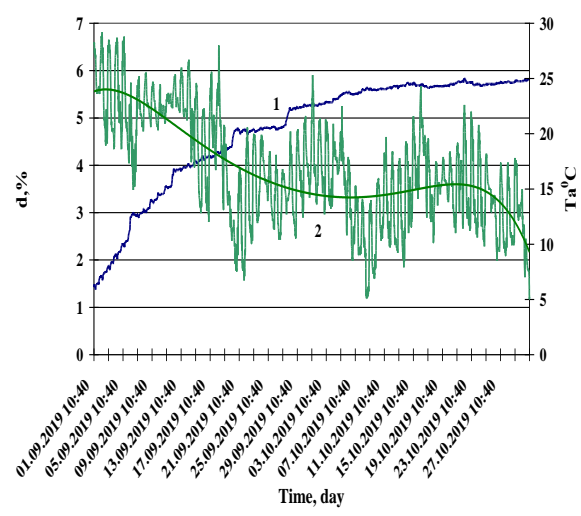

D

Fig. 4. Dynamics of trunk growth rate of Juniperus excelsa M. Bieb. and the relationship of this process with environmental factors in September-October 2019: A - features of the growth of the diameter of the trunk (d,\%); B - natural changes in the parameters d,\% (2) and air temperature (1) and trend line; $\mathrm{C}-$ is the surface of a quadratic function $\mathrm{d}, \%=\mathrm{f}(\mathrm{I}, \mathrm{Ta})$ and $\mathrm{d}, \%=\mathrm{f}(\mathrm{I}, \mathrm{Da})-\mathrm{D}$; the top of the graph shows the numerical coefficients of the nonlinear regression equations of these dependencies.

In November, the growth of $\mathrm{d}, \%$ stopped and resumed only in March of the following year. The research results are presented in table 1.

Table 1. Dynamics of changes in trunk diameter optimums and environmental factors during vegetation.

\begin{tabular}{|c|c|c|c|}
\hline \multirow{2}{*}{ Parameter, unit } & \multicolumn{3}{|c|}{ Measuring time } \\
\cline { 2 - 4 } & March-May & July-August & $\begin{array}{c}\text { September- } \\
\text { October }\end{array}$ \\
\hline $\mathrm{Ta},{ }^{\circ} \mathrm{C}$ & $20-26$ & $22-28$ & $17-25$ \\
\hline $\mathrm{Da}, \mathrm{kPa}$ & $0.4-1.2$ & $1.8-2.5$ & $0.3-1.5$ \\
\hline $\mathrm{I}, \mu \mathrm{mol} / \mathrm{m}^{2} \mathrm{~s}$ & $300-900$ & $500-1000$ & $400-800$ \\
\hline $\mathrm{d}, \%$ & 8.83 & 4.74 & 4.39 \\
\hline
\end{tabular}


During the studied vegetation period, the value of the trunk diameter of the studied species in March-May increased at the first peak of $1 \%(0.68 \mathrm{~mm})$, at the second one $8.83 \%(3.72 \mathrm{~mm})$ on average $0.046 \mathrm{~mm}$ per day with further reaching to the plateau.

In July - August by $4.74 \%-1.69 \mathrm{~mm}(0.054 \mathrm{~mm})$ per day, and in September - October by $4.39 \%-1.53 \mathrm{~mm}(0.034 \mathrm{~mm})$ per day relative to the base value. The optimal air temperature in March - May was $20-26^{\circ} \mathrm{C}$, in July - August $22-28^{\circ} \mathrm{C}$, in September October $17-25^{\circ} \mathrm{C}$.

The optimal humidity deficit (Da) was $0.4-1.2 \mathrm{kPa}$ in March - May, 1.8-2.5 in July August, and $0.3-1.5 \mathrm{kPa}$ in September - October. Optimal illumination is $300-900$ $\mu \mathrm{mol} / \mathrm{m} 2 \mathrm{~s}$ in March - May, 500-1000 $\mu \mathrm{mol} / \mathrm{m} 2 \mathrm{~s}$ in July - August, and 400-800 $\mu \mathrm{mol} / \mathrm{m} 2 \mathrm{~s}$ in September - October.

Thus, during the studied vegetation period (2019), the increase in trunk diameter $\mathrm{d}, \%$ was $18.96 \%$ or $7.62 \mathrm{~mm}$.

When conducting research in greenhouses, the trunk diameter of Juniperus excelsa M. Bieb. at the beginning of the experiment, it was $13.38 \mathrm{~mm}$ (base value).

Throughout the year there are several phases of vegetation of the species - before the growing season (January, 31- March, 15), the first phase of active growth (March, 15 July, 27), reaching to the plateau growth (July, 27 - September, 12.09), the second phase of active growth (September, 12.09 - November, 18) with the reach the plateau of cessation of growth.

The average daily air temperature throughout the year (figure 1) also has several peaks: June-July and July-August.

The first phase of active growth (March, 15 - July, 27) of Juniperus excelsa M. Bieb is shown and the relationship of this process to the average daily air temperature is demonstrated (fig. 5). During this period (135 days), the increase in the trunk diameter $(\mathrm{d}, \%)$ was $7.12 \%(1.11 \mathrm{~mm})$ from the base value $-0.053 \%(0.08 \mathrm{~mm})$ per day. The graph shows a slowdown in the intensity of growth from April, 28 - May, 27 and from July, 13 July, 25, associated with a decrease in air temperature. After the first phase of active growth (July, 27), there is an access to the growth plateau - till September 12. This can be explained by an increase in air temperature to $28-32^{\circ} \mathrm{C}$.

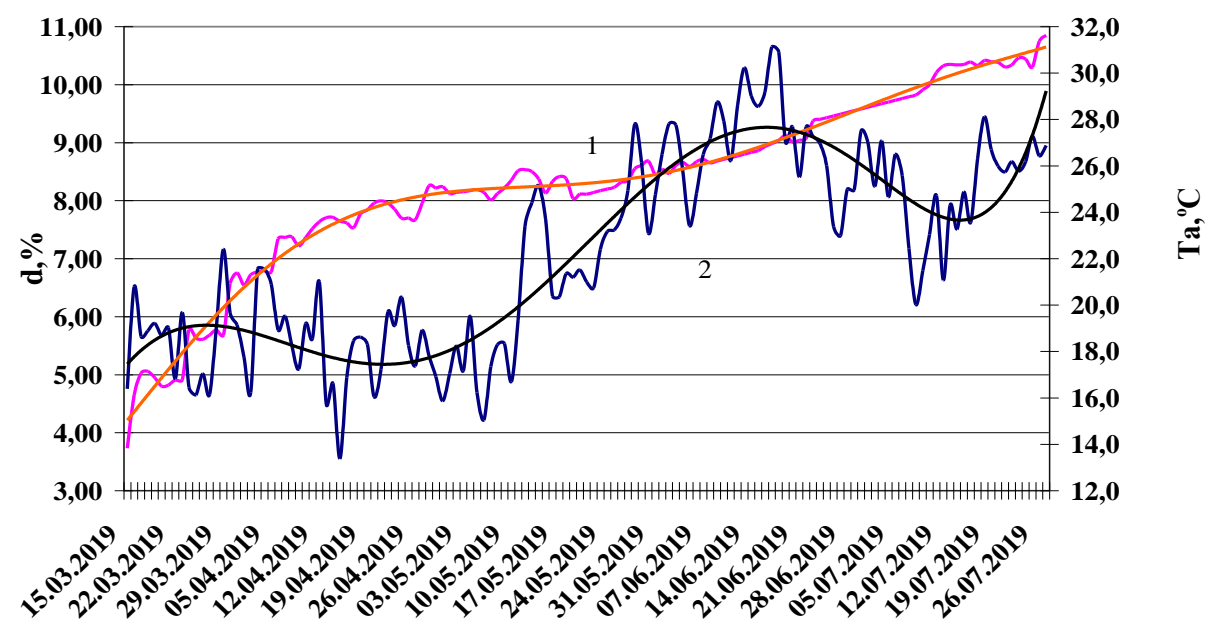

Time, day

Fig. 5. Relationship between the dynamics of trunk diameter growth (1) Juniperus excelsa M. Bieb. and the air temperature (2) and trend line in the first phase of active growth - (March, 15 - July, 27). 
The relationship between the intensity of growth of the trunk of the studied species and the parameters of the external environment - air temperature and humidity deficit in the first phase of active growth: March, 15 - July, 27 (fig. 6).

The dependence of growth intensity on total solar radiation and air temperature $\mathrm{d} \%=\mathrm{f}(\mathrm{I}, \mathrm{Ta})$ is shown, and the equation of nonlinear regression of these dependencies is given (figure 6, A). Optimal conditions for maxima and boundaries of the optimal regions are $\mathrm{Ta}=22-28^{\circ} \mathrm{C}, \mathrm{I}=500-800 \mu \mathrm{mol} / \mathrm{m} 2 \mathrm{~s}$.

The dependence of growth intensity on total solar radiation and air humidity deficit $\mathrm{d}, \%=\mathrm{f}(\mathrm{I}, \mathrm{Da})$ is shown, and the equation of nonlinear regression of these dependencies is given (figure 6, B). Optimal and limiting conditions of maxima and boundaries of growth optima regions are determined, as well as numerical coefficients of nonlinear regression equations of these dependencies-Da=1.8-2.3 $\mathrm{kPa}, \mathrm{I}=500-800 \mu \mathrm{mol} / \mathrm{m} 2 \mathrm{~s}$.
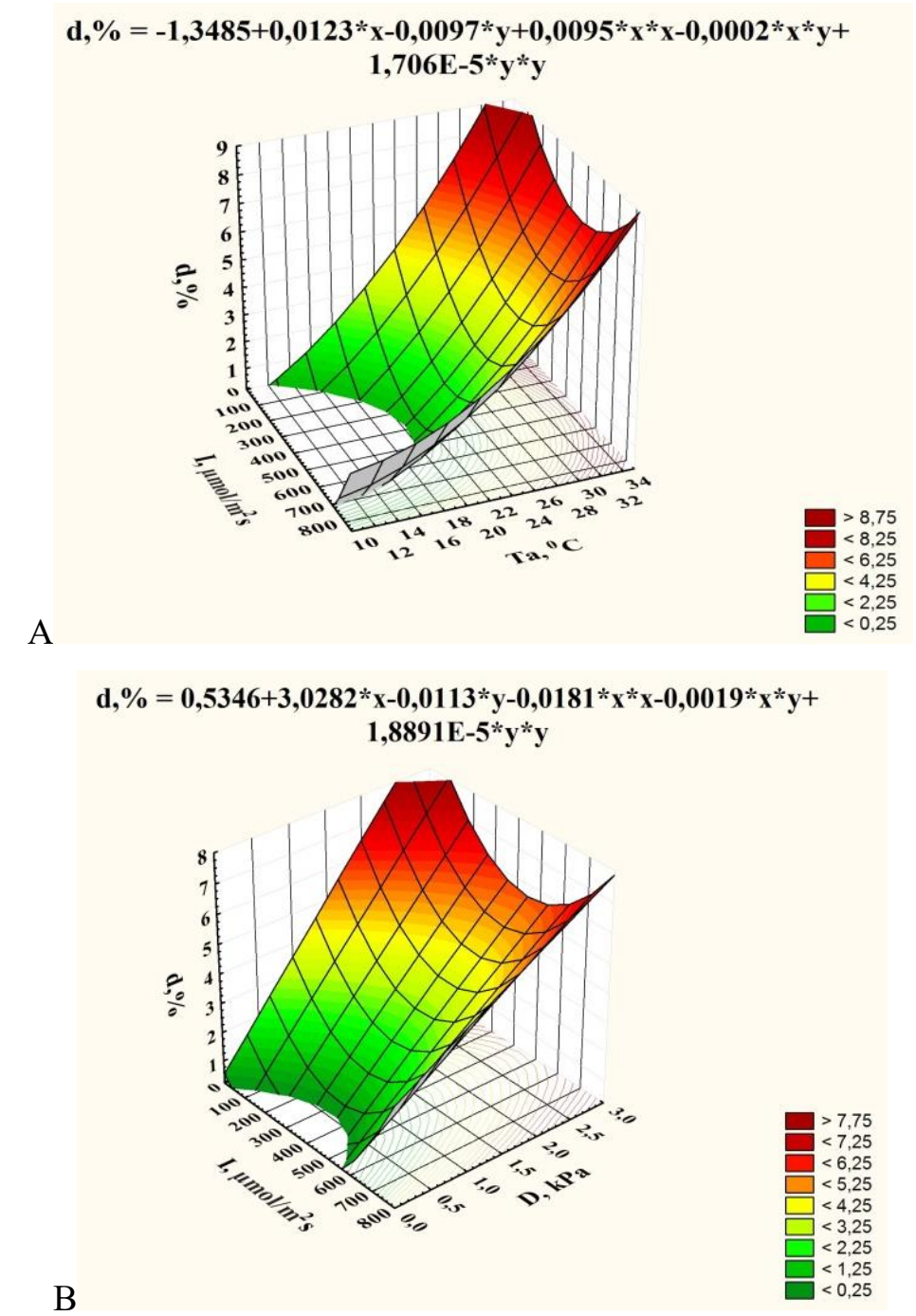

Fig. 6. The dynamics of the intensity of the growth of trunk of Juniperus excelsa M. Bieb. and the relationship of this process with environmental factors in the first phase of active growth - (March, 15 
- July, 27). A - is the surface of a quadratic function $\mathrm{d}, \%=f(I, T a) ; B-d, \%=f(I, D a)$; the numerical coefficients of nonlinear regression equations of these dependencies are shown at the top of the graph.

The second peak of active growth (September, 12 - November, 18) of Juniperus excelsa M. Bieb is shown and the relationship of this process to the average daily air temperature (fig. 7). During this period (67 days), the increase in the trunk diameter (d,\%) was $5.06 \%$ $(0.788 \mathrm{~mm})$ of the base value. The average daily increase was $0.075 \%(0.011 \mathrm{~mm})$ per day. The graph shows a slowdown in the growth rate from November, 5 - November, 14, which is associated with a decrease in air temperature (fig. 5). After the second phase of active growth (November, 14), there is the reaching the plateau and the vegetation period is resumed only in March next year.

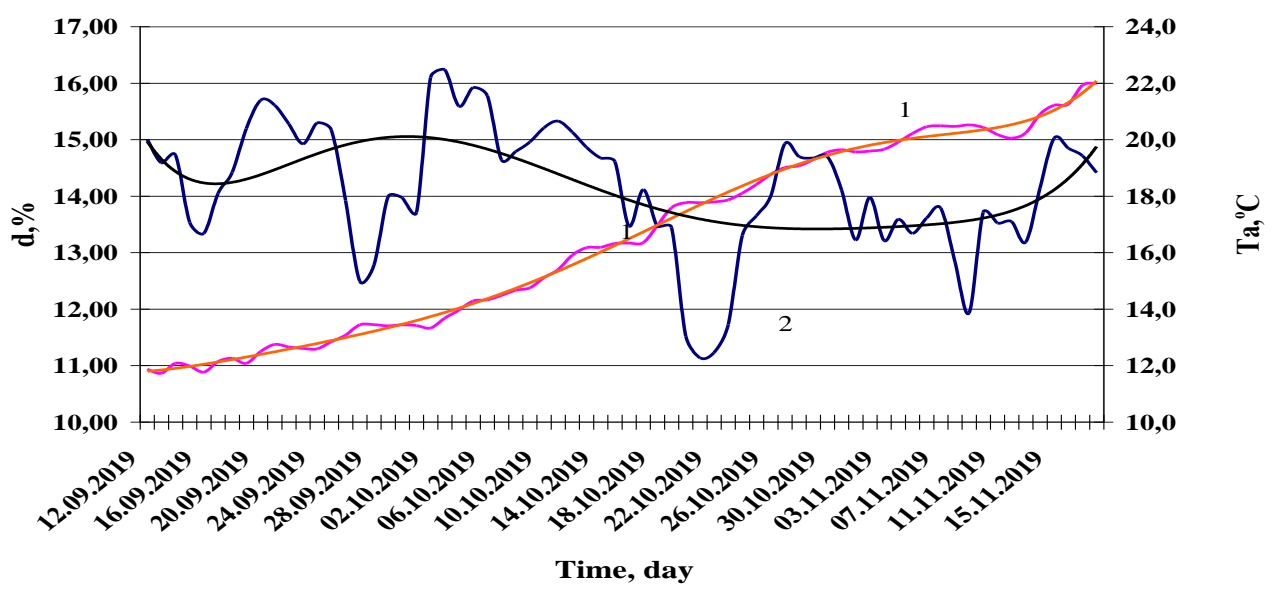

Fig. 7. The relationship between the growth of the trunk diameter (1) and Juniperus excelsa M. Bieb. and the air temperature (2) and trend line in the first phase of active growth - (September, $12-$ November, 18).

The relationship between the growth intensity of the trunk of the studied species and environmental parameters - air temperature and humidity deficit during the second period of active growth (September, 12 - November, 18) of Juniperus excelsa is shown (fig. 8).

The dependence of the growth intensity on the total solar radiation and air temperature is determined $-\mathrm{d}, \%=\mathrm{f}(\mathrm{I}, \mathrm{Ta})$ and the equation of nonlinear regression of these dependencies is given (fig. 8, A). This allowed us to determine the optimal and limiting conditions of maxima and the boundaries of the optimal growth areas $-\mathrm{Ta}=22-26^{\circ} \mathrm{C}, \mathrm{I}=400-750$ $\mu \mathrm{mol} / \mathrm{m} 2 \mathrm{~s}$.

The dependence of growth intensity on total solar radiation and air humidity deficit $\mathrm{d}, \%=\mathrm{f}(\mathrm{I}, \mathrm{Da})$ is studied, and the equation of nonlinear regression of these dependencies is given (fig. 8, B). This allowed us to determine the optimal and limiting conditions of the maxima: $\mathrm{Da}=0.3-1.2 \mathrm{kPa}, \mathrm{I}=400-750 \mu \mathrm{mol} / \mathrm{m} 2 \mathrm{~s}$. 


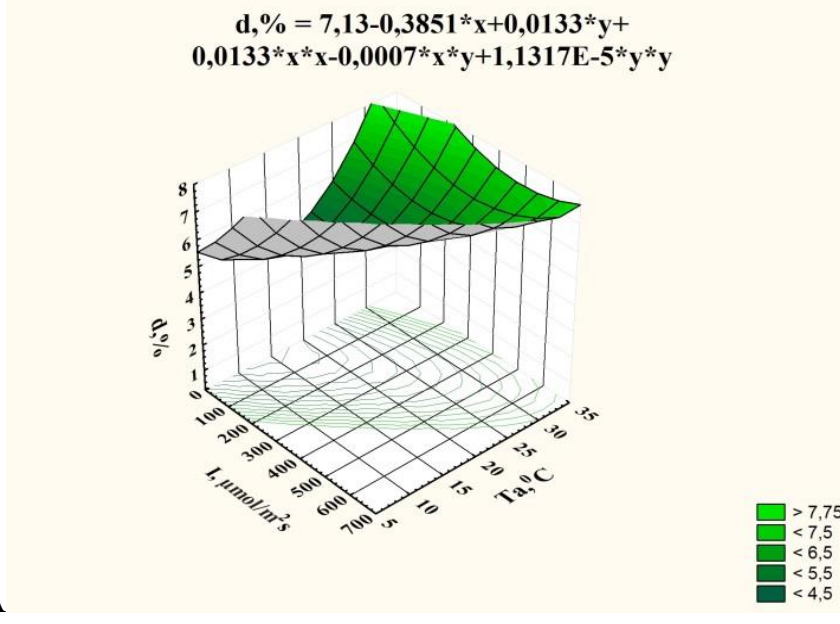

A

$d, \%=4,1998+1,0007 * x-3,0125 E-6 * y-0,0004 * x * x+3,4463 E-6 * x * y$

$-6,5393 E-9 * y^{*} y$

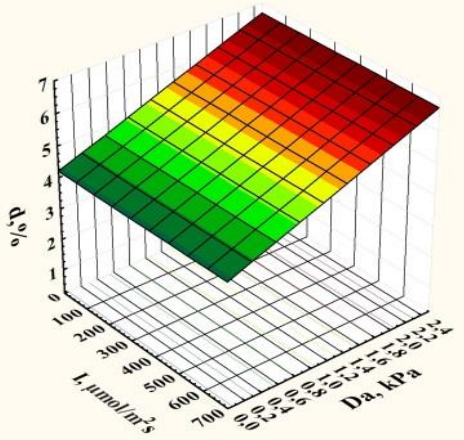

B

Fig. 8. The dynamics of the intensity of the growth of trunk of Juniperus excelsa M. Bieb. and the relationship of this process with environmental factors in the first phase of active growth -

(September, 12 - November, 18). A - is the surface of a quadratic function $d, \%=f(I, T a)$ ); $B-d, \%=f$ (I, Da); the numerical coefficients of nonlinear regression equations of these dependencies are shown at the top of the graph.

The research results are presented in table 2 .

Table 2. Dynamics of changes in the optima of the trunk diameter and environmental factors during the growing season.

\begin{tabular}{|c|c|c|}
\hline \multirow{2}{*}{ Parameter, unit } & \multicolumn{2}{|c|}{ Measuring time } \\
\hline & March-July & September-november \\
\hline $\mathrm{Ta},{ }^{\circ} \mathrm{C}$ & $22-28$ & $22-26$ \\
\hline $\mathrm{Da}, \mathrm{kPa}$ & $1.8-2.3$ & $0.8-1.2$ \\
\hline $\mathrm{I}, \mu \mathrm{mol} / \mathrm{m}^{2} \mathrm{~s}$ & $500-800$ & $400-750$ \\
\hline $\mathrm{d}, \%$ & 7.12 & 5.06 \\
\hline
\end{tabular}


During the studied vegetation period, two growth peaks of the trunk diameter of the studied species were observed: the first growth peak (March, 15 - July, 27) led to an increase in $\mathrm{d}, \%$ by $7.12 \%(1.11 \mathrm{~mm})$ from the base value $-0.053 \%(0.08 \mathrm{~mm})$ per day while there was a slowdown in growth (April, 28 - May, 27) and (July, 13 - July, 25) associated with a decrease in air temperature. The second growth peak (September, $12-$ November, 18) led to an increase in $\mathrm{d}, \%$ by $5.06 \%(0.788 \mathrm{~mm})-0.075 \%(0.011 \mathrm{~mm})$ per day - while there was a slowdown in growth (November, 05 - November, 14) also associated with a decrease in air temperature.

After the second phase of active growth (November, 14), there is an access to the growth plateau and the resumption of the growing season is resumed only in March next year.

Thus, during the studied vegetation period (2019), the increase in trunk diameter $\mathrm{d}, \%$ was $12.18 \%$ or $1.899 \mathrm{~mm}$.

Optimal and limiting values of the studied environmental parameters are found: air temperature, air humidity deficit and total solar radiation, and equations of nonlinear dependence between these parameters and the growth of the trunk diameter of the studied species are constructed.

Optimal conditions of maxima and boundaries of the optimal regions for the first growth peak: $\mathrm{d} \%=\mathrm{f}(\mathrm{I}, \mathrm{Ta})-\mathrm{Ta}=22-28^{\circ} \mathrm{C}, \mathrm{I}=500-800 \mu \mathrm{mol} / \mathrm{m} 2 \mathrm{~s} ; \mathrm{d}, \%=\mathrm{f}(\mathrm{I}, \mathrm{Da})-\mathrm{Da}=1.8-2.3$ $\mathrm{kPa}, \mathrm{I}=500-800 \mu \mathrm{mol} / \mathrm{m} 2 \mathrm{~s}$.

For the second growth peak: $d \%=f(I, T a)-T a=22-26^{\circ} \mathrm{C}, \quad I=400-750 \mu \mathrm{mol} / \mathrm{m} 2 \mathrm{~s}$; $\mathrm{d}, \%=\mathrm{f}(\mathrm{I}, \mathrm{Da})-\mathrm{Da}=0.3-1.2 \mathrm{kPa}, \mathrm{I}=400-750 \mu \mathrm{mol} / \mathrm{m} 2 \mathrm{~s}$.

\section{Conclusion}

Different climatic conditions of the greenhouse and open ground determine the growth characteristics of Juniperus excelsa M. Bieb.

During the studied vegetation period, three periods of trunk diameter growth were observed in the vegetation experiment: in March - May, two growth peaks - at the first peak $-1 \%(0.68 \mathrm{~mm})$, at the second one $-8.83 \%(3.72 \mathrm{~mm})$. In July - August by $4.74 \%$ $(1.69 \mathrm{~mm})$, and in September - October by $4.39 \%-(1.53 \mathrm{~mm})$, the increase in trunk diameter for 2019 was $18.96 \%$ or $7.62 \mathrm{~mm}$.

In greenhouse conditions, there were two growth peaks: in March - July, the first peak was an increase in $\mathrm{d}, \%$ by $7.12 \%(1.11 \mathrm{~mm})$ - while there was a slowdown in growth (April, 28 - May, 27) and (July, 13 - July, 25). The second peak is an increase in d,\% by $5.06 \%$ - and a slowdown in growth (November, 05 - November, 14). The total increase in $\mathrm{d}, \%$ was $12.18 \%(1.899 \mathrm{~mm})$.

The increase in $\mathrm{d}, \%$ in the conditions of vegetation experiment is $6.48 \%$ more than in the greenhouse conditions.

Optimal and limiting values of the studied parameters of the environment and $d, \%$ for both research variants are found, and equations of nonlinear dependence between them are constructed.

An increase in air temperature to $30-35^{\circ} \mathrm{C}$ causes a decrease in the intensity of growth with further access to the plateau.

The research made it possible to determine the optimal and limiting conditions for the growth of this species in the conditions of the Southern Coast of the Crimea and the possibility of its introduction to other regions. 


\section{References}

1. Giorgi F and Lionello P 2008 Climate change projections for the Mediterranean region Glob Planet Change 63 90 DOI: 10.1016/j.gloplacha.2007.09.005

2. Fatemi S S, Rahimi M, Tarkesh M and Ravanbakhsh H 2018 Predicting the impacts of climate change on the distribution of Juniperus excelsa M. Bieb. in the central and eastern Alborz Mountains Iran. iForest 11643 DOI: 10.3832/ifor2559-011

3. Jena A V and Feteria A V 2015 Red book of the Republic of Crimea. Plants, algae, fungi (Simferopol: LLC IT «ARIAL») p 480

4. Sperlich D, Chang C T, Peñuelas J, Gracia C and Sabaté S 2015 Seasonal variability of foliar photosynthetic and morphological traits and drought impacts in a Mediterranean mixed forest Tree Physiology 35501 DOI: 10.1093/treephys/tpv017

5. Kint V, Aertsen W, Fyllas N M, Trabucco A, Janssen E, Özkan K and Muys B 2014 Ecological traits of Mediterranean tree species as a basis for modelling forest dynamics in the Taurus mountains, Turkey Ecological Modelling 28653

6. Özkan K, Gulsoy S, Aerts R. and Muys B 2010 Site properties for Crimean juniper (Juniperus excelsa) in semi-natural forests of south western Anatolia, Turkey $J$. Environ. Biol. 3197

7. Jovellar L C, Fernández L, Mezquita M, Bolaños F and Escudero V 2013 Structural characterization and analysis of the regeneration of woodlands dominated by Juniperus oxycedrus L. in west-central Spain Plant Ecol 21461

8. Willson C J, Manos P S and Jackson R B 2008 Hydraulic traits are influenced by phylogenetic history in the drought-resistant, invasive genus Juniperus (Cupressaceae) Am J Bot 95299

9. Mayoral C, Calama R, Sánchez-González M and Pardos M 2015 Modelling the influence of light, water and temperature on photosynthesis in young trees of mixed Mediterranean forests New Forests 46485 DOI: 10.1007/s11056-015-9471-y

10. Cruz-García R, Balzano A, Čufar K, Scharnweber T, Smiljanić M and Wilmking M 2019 Combining Dendrometer Series and Xylogenesis Imagery-DevX, a Simple Visualization Tool to Explore Plant Secondary Growth Phenology Front. For. Glob. Change 260 DOI: 10.3389/ffgc.2019.00060

11. Ilnitsky O A, Plugatar Yu V and Korsakova S P 2018 Methodology, instrument base and practice of phytomonitoring (Simferopol: IT “ARIAL”) [in Russian] p 236

12. Gülcü S, Gültekin H C, Çelik S, Eser Y and Gürlevik N 2010 The effects of different pot length and growing media on seedling quality of Crimean juniper (Juniperus excelsa Bieb.) African Journal of Biotechnology 9 (14) 2101

13. Gürlevik N, Deligöz A and Yıldız D 2014 Effects of irrigation and fertilization on the growth of juniper seedlings Der Einfluss von Bewässerung und Düngung auf das Wachstum von Wacholdersämlingen Austrian Journal of Forest Science 3171

14. Karapatzak E, Varsamis G, Koutseri I, Takos I and Merou T 2019 The effect of pollen performance on low seed fertility in a Greek population of Juniperus excelsa J. For. Sci. 65356 DOI: 10.17221/42/2019-JFS

15. Öncel M, Vurdu H, Kaymakçı A, Özkan O E and Aydoğan H 2019 COATING PERFORMANCES OF CRIMEAN JUNIPER (Juniperus excelsa M. BIEB.) WOOD Cerne 25 (1) 36 DOI: 10.1590/01047760201825012599

16. Drozdov S N and Kholoptseva E S 2013 Possibilities of using a multi-factor experiment in the study of ecological and physiological characteristics of plants 
Scientific notes of Petrozavodsk state University [Uchenye zapiski Petrozavodskogo gosudarstvennogo universiteta - in Russian] 2 (131) 11

17. Boogar A R, Salehi H, Pourghasemi H R and Blaschke T 2019 Predicting Habitat Suitability and Conserving Juniperus spp. Habitat Using SVM and Maximum Entropy Machine Learning Techniques Water 11(10) 2049 DOI: 10.3390/w11102049 